\section{Community mental health teams: evidence}

\section{or belief ?}

\author{
G. THORNICROFT, T. BECKER, F. HOLLOWAY, S. JOHNSON, M. LEESE, \\ P. MCCRONE, G. SZMUKLER, R. TAYLOR and T. WYKES
}

We welcome the publication of the commentary by Marshall et al (1999, this issue) on our PRiSM Psychosis Study reports (BJP, 173, 363-427; November 1998) for two reasons: it allows us to refute the flawed basis of their paper and, more importantly, it stimulates further discussion about the meaning of the research conducted on community mental health teams (CMHTs). We shall suggest that the implications of this research are not yet clear and consistent, and that many firmly-held beliefs which are not evidence-based persist about CMHTs.

\section{QUESTIONS OF MISTAKEN IDENTITY}

The authors of the commentaries (Marshall et al, 1999, this issue; Sashidharan et al, 1999, this issue) on our papers base their critiques on a series of mistaken propositions, and they then attempt to deconstruct the 'straw man' that they themselves have built. First, they assert that we presented an evaluation of an assertive community treatment (ACT) service. This is wrong. As we go to considerable lengths to describe in our ten papers, what we have done is to evaluate, across two time points, two contrasting models of service for patients suffering from psychotic disorders in whole catchment areas, rather than for any selected subgroup of patients. Although one of the teams in one of the study areas the psychiatric assertive continuing care (PACT) team (Becker et al, 1998a) - in some respects resembles the ACT model, our study as a whole is not an ACT evaluation. Indeed, we did not study the effects of circumscribed CMHTs of any type, but rather the effects of two whole systems (which were provided in two geographically defined catchment areas) that were

'See pp. 501-507, this issue. characterised by different models of care. We have, therefore, not extended the discussion of our results to the implications for ACT or intensive care management (ICM) models per se. By contrast Tyrer (1998), in an earlier commentary on our study, does, somewhat mistakenly, draw such wider implications.

Sashidharan et al further assert that we did not clearly describe the interventions used; in fact we dedicated a whole paper to describing the work of the services in great detail (Becker et al, 1998a). They also suggest that the authors of the PRiSM Psychosis Study papers assumed two premises: that efficacy in this field of study over-estimates effectiveness; and that previous studies produced 'distorted' results. In neither case is their assertion correct. In fact we tested both these points empirically, using them, among others, as hypotheses for scientific scrutiny, not as initial premises.

The second misunderstanding in Marshall et al's commentary relates to their belief that the study should have included only more severely disabled patients with psychosis. Our intention was precisely the opposite: to compare the effects of treatment (and lack of treatment) by a single, generic CMHT with the effects of a model comprising two CMHTs, and to compare both approaches across time with the previous hospital-based models. All three service configurations are firmly rooted in the National Health Service (NHS) approach to providing mental health care, in that they are intended to apply to all relevant members of the local population with severe mental illness, regardless of eligibility criteria, features not always present in some evaluations of CMHTs (Schinnar et al, 1990). Indeed, we have deliberately not constrained clinical practice such that patients only remained in contact with the psychiatric acute care and emergency (PACE) or PACT teams throughout the study period. On the contrary, the two teams in the intensive sector transferred patients between them on clinical grounds. This fully reflects what happens in routine clinical practice, where there is very often continuing pressure to move patients between acute and continuing care teams, especially from the former to the latter. It would have been clinically unrealistic to attempt to tell clinicians to keep patients in contact with one or other of the teams.

The third criticism made by Marshall et $a l$ is that the services did not differ. Again, this is not the case. The major differences were as follows. First, the Nunhead (intensive) service had a substantially different way of working: using two teams, one specialising in acute and the other in continuing care. Second, the Nunhead service developed better links with primary care. Third, there was a greater amount of user involvement in the Nunhead service. Finally, the Nunhead service was somewhat more expensive than the Norwood Service (McCrone et al, 1998).

Marshall $e t$ al, in a fourth objection to our study, feel that we have overstated the strengths of the study. They attempt to detract from each of the six points that we have raised. Unfortunately, they again overstate their case. We have not claimed that our study is unique in each and every one of these respects; rather, we have suggested that these six areas are strengths of the PRiSM Psychosis Study, shared in part by other previous work, but also that this study is unique in that these six characteristics are combined within a single investigation.

Indeed, the epidemiological base of the study, in which all annual-period prevalent cases of psychosis were ascertained as far as possible, does mark a methodological advance over recent previous work. It allows us to estimate the proportion of true prevalent psychosis cases which were in contact with any service at baseline, and at follow-up, and to investigate whether those cases out of contact with services were less or more disabled than those remaining in contact. Our study is, therefore, unusual in that it addresses the question of the capacity of the whole-sector service in relation to population-level need.

With respect to a key proposition made by Marshall et al, namely that a "client to staff ratio of 10:1 is accepted as optimal for an ACT team by experts . . . and is nearly universally adhered to in practice", we take issue. This has certainly been a frequently repeated belief, asserted by those 
within the ACT field, but the empirical evidence is not compelling. The most extensive recent study focusing specifically on this question (UK700 Group, 1999a) signally produced negative findings when comparing keyworker case loads of 15 and 30 in delivering ICM.

On three points we do agree with Marshall et al. First, in terms of how far the services incorporated in practice the values that were intended when the services were designed, we accept that these ratings were subjective, and that they were not made using an instrument with adequate psychometric properties. Indeed, despite 20 years of detailed international work on different aspects of community mental health services, there is no standard overall nomenclature or taxonomy for mental health services which allows service components, or whole systems of care, to be compared in a standardised way between different areas. Recent work is beginning to remedy this methodological deficit (Johnson et al, 1998b). Furthermore, the commentary raises the objection that the baseline measures and follow-up measures were staggered rather than historically contemporaneous. This is quite true, since the CMHTs were introduced in a staggered way, and consequently valid baseline and follow-up measurements needed also to be staged in turn. This again is a common feature of real-world clinical interventions which are applied in different areas at different times.

A number of subsidiary points were raised, including the modest follow-up rate, the high levels of geographical mobility, and the lack of control over external events, such as the introduction of the Supervision Register. These study limitations are fully acknowledged and discussed in our reports (Thornicroft et al, 1998b), along with strong evidence that despite the relatively high drop-out rate, those patients who were interviewed at follow-up were reasonably representative of those randomly selected for interview from among all prevalence cases of psychosis in the local catchment area (Thornicroft et al, 1998a, Table 4).

Marshall et al raise further questions about the limitations in matching the two sectors. There is some substance in this point. As the first paper in the PRiSM series (Thornicroft et al, 1998a) spells out, the overall total populations for the two study sectors were remarkably similarly when matched a priori. It became clear a posteriori, however, that the sub-populations of patients with psychosis within those two whole areas were not as closely matched as were the total populations. This was an unexpected finding, and one that was impossible to predict at the beginning of the study, before case ascertainment had been undertaken. At the same time, the detailed information we have on the patients allows us to militate to some extent against incomplete matching by adjustment at the analysis stage - as we have done, for example, in the paper reporting social disability scores (Wykes et al, 1998). This is indeed a limitation of quasi-experimental, naturalistic studies, which we acknowledge and discuss (Thornicroft et al, 1998b). At the same time, the transition from randomised control trials (RCTs) at the level of individual patient or staff member to evaluations at the level of whole-service systems for entire patient populations raises an unenviable trade-off. The greater degree of applicability to whole clinical populations achieved by quasi-experimental designs is achieved at the cost of the many advances of RCTs in terms of reduction in bias and error (Taylor \& Thomicroft, 1996). It is a dilemma faced by all those who undertake evaluations of complex interventions in health services research (Bradley et al, 1999).

The commentary by Sashidharan et al warrants comment in its own right. Those authors suggest that the results of the PRiSM Psychosis Study give succour to those who suggest that community care has failed. Not only is this not our view (Thomicroft \& Goldberg, 1998), it is explicitly not what we concluded in our study, as stated in the abstract of Thornicroft $e t$ al (1998b): "The health and social gains reported in experimental studies of community health services are replicable in ordinary clinical settings, and are more effective than hospital-oriented services which they replace". It is somewhat puzzling that Sashidharan et al should read the results of this study and somehow draw the opposite conclusions from those stated.

\section{WHAT IS ASSERTIVE COMMUNITY TREATMENT?}

The proponents of ACT have recently set out a series of definitions of it. The PRiSM Psychosis Study was designed in 1991, before these descriptions were published; nevertheless, we discuss in this section how far the model of our PACT team is consistent with current views on programme fidelity to the ACT model. We draw on two overlapping typologies of ACT (Deci et al, 1995; Teague et al, 1998). An examination of our PACT team in terms of the Deci criteria yielded the following results.

The number of potients cared for by the programme. Stein \& Santos (1998), for example, suggest that this should be in the region of 100 patients, with ten core staff. The PACT team had a broader remit than the focus expected of an ACT team, and had staffing of ten whole-time equivalents, which is in line with recommendations (Stein \& Santos, 1998), with a keyworker to patient ratio of $1: 13$.

Services provided 24 hours a doy, seven doys a week. Direct care or phone duty response was provided by PACT throughout these hours.

Team members con deliver medication daily if necessory. This criterion was met, although daily medication delivery was rare in practice.

Potients can graduate to less intensive interventions or be discharged from the programme. In the first two years of the PACT team, which were the ones studied in the evaluation, relatively few cases were discharged, and indeed the issue of discharge from ACT is an emerging theme in the literature (see Salyers et al, 1998). There is little evidence on this point to date, although from a managerial perspective 'step down' services are vital in order to make ACT clinically viable.

The team includes psychiatrists and nurses. Criterion met.

The team arronged or directly manoged potients' finonces. This was not done, and is not common in the UK because of rules over welfare benefits, and patients' concerns over civil liberties.

The averoge percentoge of team activity which tokes place in the community. This is targeted at $80 \%$; that reported by our PACT team was $50-70 \%$.

The PACT team, therefore, meets many, but not all, of the criteria proposed 
Table I Programme criteria for the psychiatric assertive continuing care (PACT) team's fidelity to assertive community care (ACT) (see Teague et ol, 1998)

\begin{tabular}{|c|c|}
\hline Criterion & PACT team in Nunhead sector \\
\hline $\begin{array}{l}\text { Small caseload (10:1 staff : patient } \\
\text { ratio) }\end{array}$ & PACT nurse keyworkers' caseload I3:I \\
\hline Team case-working & PACT implemented UK policy in keyworker role, not team case-working \\
\hline Programme meetings & PACT meets regularly to review patient progress, with daily team meetings \\
\hline Practising team leader & Yes \\
\hline Continuity of staffing & Variable, with relatively high staff turnover, as is common in London (Johnson et al, 1997) \\
\hline Staff capacity & Full capacity except problems in recruiting a psychologist during the study period \\
\hline Psychiatrist on staff & Yes \\
\hline Nurse on staff & Yes \\
\hline Substance misuse specialist on staff & No \\
\hline Vocational specialist on staff & Occupational therapist is a key component with links to available vocational rehabilitation \\
\hline Explicit admission criteria & Patients admitted with severe mental illness already known to local services, and had previous hospital admissions \\
\hline Intake rate & Low admission rate to team \\
\hline Full responsibility for treatment & PACT very comprehensive (except for other statutory responsibilities: e.g. care management, Disability Employment \\
\hline services & Advisor) and included crisis house and respite house \\
\hline Responsibility for crisis services & Yes \\
\hline Responsibility for hospital admissions & Yes \\
\hline Responsibility for discharge planning & Yes \\
\hline Time-unlimited services & Yes \\
\hline In-vivo treatment, e.g. at home & Yes \\
\hline 'No drop-out' policy & Partly; agreed discharges allowed \\
\hline Assertive engagement & Yes \\
\hline Intensity of services & Titrated to assessed need \\
\hline Frequency of contact & Health economic data confirm that individuals in PACT received daily nurse visits (McCrone et al, 1998) \\
\hline Work within support system & Active work with other agencies (e.g. teaching a course for housing workers (Becker et al, 1998)) \\
\hline $\begin{array}{l}\text { Substance misuse treatments within } \\
\text { team }\end{array}$ & No. Recent addition to ACT model. No UK evidence base \\
\hline
\end{tabular}

by Deci et al (1995) as necessary for an ACT team. The second proposed set of criteria for qualification as an ACT team is that of Teague et al (1998) and Table 1 shows how far our PACT team continues to meet them.

To these criteria we could add those of Rapp (1998). The outcome is that although the PACT team does partly match some of these criteria in some of these definitions, there are also important respects in which it differs. It did not adopt a team approach to the whole case load, which according to Mueser et al (1998) is a core requirement of ACT, but which may not be compatible with guidance on the implementation of the Care Programme Approach (CPA) in the UK. Case loads were also rather higher, although in the UK ICM literature there appears to be no benefit in patient to staff ratios of 8:1 v. 30:1 (Holloway \& Carson, 1998) or 15:1 $\nu$. 30:1 (UK700 Group, 1999b). Finally, our study differed from ACT evaluations in that it did not produce positive results to differentiate the two CMHT models.

\section{CLINICALLY REALISTIC CMHT MODELS: CONFLICTING OR ABSENT EVIDENCE}

Beyond the debate about this particular study, it is important also to address the wider question of what research on CMHTs means for planners, clinicians, patients and carers. In practice there is an astonishing variety in how CMHTs are implemented, at least in the UK (Sayce $e t$ al, 1991; Johnson \& Thomicroft, 1995). In a thoughtful review of the field, Kluiter (1997) abandons any attempt to use a consistent typology for CMHTs and refers to them in aggregate as 'community care arrangements'. We are less pessimistic and propose that, in real clinical practice, most sites can be considered to have one of the following seven types of model. (a) Generic, multi-disciplinary CMHTs

(b) Generic CMHTs, supplemented by a crisis/home treatment team

(c) Generic CMHTs, supplemented by an ACT team

(d) Generic CMHTs with an ACT team and a crisis/home treatment team.

(e) Generic CMHT including augmented crisis or ACT functions

(f) Separate specialist teams providing specialist forms of treatment to subgroups of patients

(g) Specialist staff in particular evidencebased treatments placed in generic teams

We shall consider in turn each of these seven models in terms of the evidence base (where it exists), and their relative advantages and disadvantages.

\section{Generic multi-disciplinary CMHTs}

In most of the UK, generic CMHTs now appear to be the basic building block for community mental health services. A 
current unresolved question is whether they should operate on the basis of geographical or primary care list boundaries. The simplest model of provision of community care is for generic CMHTs to provide the full range of interventions to aduits aged 18 -65 years with severe mental illness in a local sector (defined geographical catchment area).

Evidence from the UK (Tyrer et al, 1995; Tyrer, 1998) suggests that there are benefits to the introduction of generic community-based multi-disciplinary teams, essentially working on the basis of the CPA. This may improve engagement with services, and possibly reduce suicide, though there is no clear evidence of significant benefits for clinical and social outcomes. So far, there is no clear evidence from the UK that more intensive models such as ACT and ICM are really superior to good-quality basic care by CMHTs implementing the CPA.

The central advantages of the provision by generic CMHTs of a full range of services, rather than the devolving of some functions to other teams, are in continuity of care and flexibility. Patients may benefit from seeing the same staff long-term; and, when in crisis the relationships staff have already established may be invaluable. The generic CMHT is flexible in that intensity of input may be varied according to the patient's current needs without requiring transfer to another team. There may be patients who will benefit from frequent contact and outreach, for example during a relapse, but who at other times require relatively low levels of input. Scope for providing such flexibility may be diminished by the use of separate outreach teams, which have a remit to provide intensive support.

A further advantage of comprehensive care provision by generic teams is that the service structure is relatively straightforward and readily understandable by other agencies as well as by patients and carers. As the catchment populations will be relatively small (usually $40000-50000$ people in the UK), generic CMHTs are well placed to get to know well the area and the other agencies working within it.

Providing a full range of types of intervention to the population of a sector may make too many demands on staff skills it may be difficult, while working in a generic team, to develop a high level of skill in crisis working or in engaging difficult patients. Staff may wish to specialise in the type of work they most enjoy and feel suited to, such as long-term care or crisis intervention. Also, many staff who have chosen to work in CMHTs may not be keen to undertake the extended working hours which are needed for the management of emergencies and for ACT.

\section{Generic CMHTs supplemented by a crisis/acute home treatment team}

In order to improve emergency response and to manage emergencies as far as possible in the community, various forms of specialist team have been developed. Some of these concentrate exclusively on multidisciplinary crisis assessment, often in patients' homes, with immediate onward referral. However, the model which may be of greater interest is intensive home treatment, in which assessments are usually followed by intensive management of the crisis in patients' homes, with frequent visits for assessment, monitoring and treatment. Two examples of such teams are those reported by Dean \& Gadd (1990) and by Minghella et al (1998). At their most intensive, such teams may be available 24 hours a day and have the capacity to visit more than once a day if required and to spend long periods at patients' homes.

Burns et al (1993) reported a comparison of a community-based model in which initial assessment of patients took place at home with a more hospital-based style of treatment, which was usual for the NHS at the beginning of the $1990 \mathrm{~s}$. There were no differences in clinical and social functioning, but the authors did find better attendance for initial assessments and significantly lower costs in the communitybased group, and a related reduction of in-patient care.

Merson et al (1996) studied 100 patients who were randomly allocated between a standard, relatively hospitalbased, service and a multi-disciplinary community-based team providing acute care of a moderate level of intensity. The community-based model was less costly and preferred by patients, and was associated with greater symptom improvement.

There is, therefore, some evidence that intensive home treatment, which may involve visiting patients more than once a day, is safe and feasible for many, although probably not all, acutely ill patients, and that such treatment is likely to reduce hospital time and costs. This type of treatment also appears to be preferred by service users and carers, who tend to place a high priority on having rapid, 24-hour-a-day access to emergency assessment and intervention at home. The existence of crisis teams, particularly out of hours, may reduce the burden of working in generic CMHTs, in that keyworkers will not have to manage acutely ill patients in the community single-handed, and will also have someone to pass responsibility on to when they go home. At the same time, the cost to staff (in terms of burn-out and the effect on morale) of working in emergency teams at the weekend and at nights is unknown. Most of the questions relating to this model which are important for practice and policy remain unanswered by research.

\section{Generic CMHTs, supplemented by an ACT team}

ACT teams are perhaps the most extensively described and evaluated model of community treatment, at least in the USA (Lehman et al, 1995, 1998). An open question is how far this model can be distinguished from services which are described as ICM, where case loads are similarly low, but where the emphasis is on case work by individual keyworkers rather than on a team approach. Whether one sees these two models as genuinely distinct is important, in that the evidence for the effectiveness of the services which have been described as ICM has tended to be somewhat less convincing than that for the effectiveness of ACT (Brugha \& Glover, 1998). Again, the absence of a standard classification of services limits valid conclusions. Marshall et al (1997a), for example, took the unusual view that ICM does not include services that offer home treatment, a distinction rejected by Mueser et al (1998).

ACT teams are disappointing on some dimensions of outcome-for example, there is little evidence that they produce benefits in terms of symptoms or social functioning. Although there are promising findings from North America and Australia about this form of care, its superiority to (for example) good-quality generic CMHTs provided in areas where the CPA functions well has not yet been demonstrated. Even if we assume that some patients do benefit from ACT, we do not yet know whether it is a useful model in every geographical context - in rural areas, for example.

The evidence also remains unclear as to whether ACT is a solution for the most difficult patient groups of all - those who lack insight into their illnesses, are deeply hostile 
to statutory services, repeatedly refuse to let mental health workers into their homes, and who have serious histories of violence. The efficacy of ACT and intensive forms of community care in preventing suicide, violence and homicide has not so far been established. It is conceivable also that wider cultural influences have an impact upon treatment appropriateness - privacy tends to be highly valued in the UK, for example.

Furthermore, many North American services do not have clinical responsibility for a whole catchment area, so that the patient populations treated by their ACT services may be somewhat selected (Essock et $a l, 1998$ ). The consequences of ACT for the whole system of local services also need to be weighed: where funding is constrained, ACT may tie up considerable resources in the care of a relatively small subgroup of patients. This may result in a loss of flexibility in treating other patient groups, particularly those who may benefit intermittently from a more intensive input, but for whom it is not a long-term continuing requirement.

The creation of multiple teams also creates considerable scope for boundary disputes, difficulties over allocation between teams, and resentment from other staff of the 'special' working conditions of ACT teams. Finally, initial evidence on ACT suggests that the gains from it are not sustained once this high-intensity treatment is withdrawn and patients are discharged to generic community care. ACT does not, therefore, appear to bring about lasting change. ACT is, in essence, more a way of organising the delivery of treatments than a specific form of treatment in its own right.

\section{CMHT with ACT and crisis/acute home treatment teams}

This model combines the two models described immediately above (i.e. the generic CMHT plus crisis acute home treatment team, and the generic CMHT plus ACT team). An example is the North Birmingham service (Minghella et al, 1998; Sainsbury Centre for Mental Health, 1998). The presence of an assertive outreach (this term is usually used as if it is synonymous with ACT) team may be important to the continued good functioning of crisis teams, in that it allows them to refer their more difficult patients to a service which can provide them with a high level of input. A disadvantage is the relative complexity of this model for service users and for referrers; another is the fact that transfers between one team and another will be relatively frequent, resulting in disruptions to therapeutic relationships. This combined model has not been reported in peer-reviewed publications.

\section{Generic CMHTs with augmented crisis and/or ACT functions}

A further model involves one generic CMHT team designating specific staff, or portions of staff time, for crisis or for ACT functions in a hybrid fashion. Although such a blend is commonly found in clinical practice, it is not described in the research literature.

\section{Separate teams providing specialist forms of treatment to subgroups of patients}

Research on service organisation in the past ten years suggests that different forms of community service organisation make relatively little impact on patients' overall clinical and social outcomes. The gains that are achieved are generally not sustained after the intervention is finished. Recent literature suggests, perhaps not surprisingly, that specific treatment interventions appear to have a somewhat greater impact on patient outcomes than do variations in service organisation (Goldman et al, 1994). Emerging treatment models which may have direct beneficial effects on the course of severe mental illness (particularly schizophrenia) include early intervention methods, family treatments, medication compliance, and cognitive-behavioural therapy. Benefits have also been shown for some dual diagnosis interventions and for vocational rehabilitation (see, e.g., Lehman et al, 1995, 1998). A crucial question which therefore arises for service organisations is how to plan services in order to allow delivery of these specific treatments to those who will benefit. Combinations of multiple specialist teams await proper evaluation in terms of their impact on whole patient populations.

\section{Specialist staff in particular evidence-based treatments placed in generic teams}

The development of specialist teams has disadvantages in making local service structures complex, and in some areas there are simply insufficient numbers of staff to constitute more than one CMHT. An alternative is, therefore, to develop a capacity for the provision of specialist interventions within the generic teams, or within ACT or crisis or home treatment teams. This can take place either through training all the team, or through encouraging different specialisations among different members of the team. Such specialisation is increasingly common in practice in the UK, but again has not been subject to formal evaluation.

\section{IMPLICATIONS FOR CMHT RESEARCH AND PRACTICE}

Mueser et al (1998) produced a comprehensive review of the evidence on different models of community care provision and case management, and they did not see ACT and ICM as very clearly distinct models. Their overview suggests that the evidence favours ACT over ICM, although the case is not overwhelmingly strong. In most studies the implementation of these models brings about a reduction in time in hospital, and findings on user satisfaction suggest that users prefer ACT and ICM to the more traditional services. Evidence on symptoms is more equivocal, but just favours ACT. There is little evidence of beneficial effects on social or vocational functioning from either type of service. Overall, the benefits of ACT and ICM do not appear to be well sustained after these services are withdrawn. Looking at trends over time, the impression is that earlier studies show more clearly positive results. In other words, it appears that the quality of the care provided to those in the control condition (standard treatment) may be improving in these studies as time passes (Burns \& Priebe, 1999).

The precise nature of individual interventions delivered is often unclear, so that it is difficult to identify 'active ingredients'. The nature of control interventions is specific to a still lesser degree, again leading to considerable uncertainty about the critical factors which lead to better results. From this and other reviews and literature, it emerges that little evidence is available regarding the implementation of these models in the UK, and, in particular, how these models compare with standard community care under the CPA (Lewis, 1997).

We can recognise two overall research strategies in the evaluation of CMHTs. The first is to identify what is beneficial in experimental conditions, and then to implement service variants in more routine clinical situations, while monitoring programme fidelity. The second is to take current real-world 
CMHTs and measure their impact directly in terms of patient outcomes. Both approaches may be able to contribute to knowledge in this field. How ACT fares in the UK has not been established, and the effective ingredients of ACT are based more on expert opinion than on evidence. Nevertheless, in the PRiSM Psychosis Study we have shown that the two models of care differ little in their impact on individual patients, and that both are superior to the previous hospital-based model of care. Future research may need to compare the seven variations of CMHT that we have described, in so far as they relate to real clinical practice, in order to examine how far they can offer effective delivery of treatments that work.

\section{REFERENCES}

Decleer, T., Hollowny F., McCrome, P., et al (19\%8) Evolving service interventions in Nunhead and Norwood. PRiSM Psychosis Study 2. British journal of Psychiatry, 173, 371-375.

Bradies, F., Wiles, R., Kinmouth, A.-L., ef of (I999) Development and evaluation of complex interventions in health service research: case study of the Southampton Heart Integrated Care Project (SHIP). British Medicol jound. 318, $711-715$.

Brughe, T. \& Clower, G. (1990) Process and health outcomes: need for clarity in systematic reviews of case management for severe mental disorders. Health Trends, 30, 78-79.

Burne, T., Beadumoore, A., Bhat, A.V., of al (I9S3) A controlled trial of home-based acute psychiatric services. 1: Clinical and social outcome. British joumol of Asychiotry 163, 49-54.

- Prlabe, S. (1999) Mental health care failure in England. Myth and reality. British fournal of Psychiotry. 174, $191-192$.

Daan, C. \& Gadd, C. (IS90) Home treatment for acute psychiatric illness. British Medical fournal, 301, $1021-1023$.

Ded, P. A., Santios, A. B., Hlott, D.W., $x$ of (19\%5)

Dissemination of asser tive community treatment programs. Pyychiotric Services, 46, 676-678.

Emock, S., Frtaman, L. K. \& Kontod, N. J. (I\%) Costeffectiveness of asser tive cormmunity treatment teams. Americon journal of Orthopsychiatry, 68, 179-190.

Coldman, H., Morrtaeen, J. \& Rdtabs S. (1994) Evaluating the Robert Wood johnson Foundation Program on Chronic Mental Illness. Millbank Quarterly, 72, 37-48.

Holloway, F. \& Carson, I. (1990) Intensive case management for the severely mentally ill. Controlled trial. British fournal of Psychiotry, IT2, 19-22.

Johruson, 5. \& Thornicroft, G. (19s5) Emergency psychiatric services in England and Wales. British Medical Journol, 311, 287-288.

—, Broola, E., Ramay, R., of el (1997) The structure and functioning of London's mental health services. In London's Mental Heolth (eds S. Johnson, R. Ramsay, G. Thornicroft, et $a$ ), pp. 22-249. London: King's Fund.

- Lewe, M, Brooks, L., et al (I9sed) Frequency and predictors of adverse events. PRiSM Psychosis Study 3. British journol of Asychiotry, I73, 376-384.

G. THORNICROFT, MRCPsych, T. BECKER, PhD, Section of Community Psychiatry (PRiSM), Institute of Psychiatry, London; F. HOLLOWAY, FRCPsych, Maudsley Hospital, London; S. JOHNSON, MRCPsych, Department of Psychiatry \& Behavioural Sciences, University College London Medical School, London; M. LEESE, PhD, P. McCRONE, MSc, Section of Community Psychiatry (PRiSM), Institute of Psychiatry, London; G. SZMUKLER, FRCPsych, Maudsley Hospital, London; R. TAYLOR, MRCPsych, Department of Psychiatry, Institute of Psychiatry, London; T.WYKES, PhD, Department of Psychology, Institute of Psychiatry, London

Correspondence: Professor Graham Thornicroft, Institute of Psychiatry, De Crespigny Park, London SE5 8AF. Tel: 0171-919 2610; Fax: 0171-2771462

(First received 22 March 1999, final revision 26 May 1999, accepted 26 May 1999)

-, Salvedor-Carvla, L. \& the EPCAT Group (19986) Description and classification of mental health services: a European perspective. Europeon Psychiotry 13, 333-341.

Kluiter, H. (IS)T) Inpatient treatment and care arrangements to replace or avoid it - searching for an evidence-based balance. Current Opinion in Psychiotry 10. 160-167.

Lehman, A. F., Thompson, J.W., Dixon, L. B., et ol (1995) Schizophrenia: treatment outcomes research editors' introduction. Schizophrenia Bulletin, 21, 561-566.

-, Steimmach, D. M. \& the Co-Imveatigators of the POim Profoct (199) Translating research into practice: the schizophrenia Patient Outcomes Research Team (PORT) treatment recommendations. Schizophrenio Bulletin, 24, $1-10$.

Lewis, G. (1997) Invited commentary on: Closing the gap between research and practice. New evidence is required. British journal of Pychiotry I7I, 227.

Marshall, M., Gray, A., Lockwood, A., of ol (1997a) Case management for severe mental disorders. In Schizophrenio Madule of the Cochrane Datobose Systematic Reviews (eds C. E. Adams, L. Duggan, J. de jesus Mari et on. Oxford: Update Software.

_, _, _, et al (1997b) Assertive community treatment. In Schizophrenio Module of the Cochrone Database Systemotic Reviews (eds C. E. Adams, L. Duggan, J. de lesus Mari et of). Oxford: Update Software.

_., Bond, G., Stain, L. l., et al (I999) PRiSM Psychosis Study. Design limitations, questionable conclusions. British foumal of Psychiatry, 175, 501-503.

MeCrone, P., Thornicroft, G., Phelan, M., et of (1998) Utilisation and costs of community mental health services. PRiSM Psychosis Study 5. British journal of Psychiatry 173, 39!-398.

Merson, S., Tyrer, P., Carien, D. et of (I996) The cost of treatment in psychiatric emergencies: a comparison of hospital and community services. Psychological Medicine, 26, 727-734

Minghella, E., Ford, R., Freerman, T., et al (1998) Open All Hours: 24-hour Response for People with Mentol Health Emergencies.London: Sainsbury Centre for Mental Health.

Mueser, K. T., Bond, G. R., Drabe. R. E, of of (I998) Models of community care for severe mental illness: a review of research on case management. Schizophrenio Bulletin, 24, 37-74.

Rapp, C. (1999) The active ingredients of effective case management: a research synthesis. Community Mentol Health foumal, 34, 363-380.

Sainabury Centre for Mental Health (1998) Keys to Engogement.London: Sainsbury Centre for Mental Health.

Salyors, M., Mastertion, T. W, Felette, D. M., ot of (I990) Transferring clients from intensive case management: impact on client functioning. Americon journal of Orthopsychiatry, 68, 233-245.

Sachicharan, S. P., Simyth, M. Omen, A. (1999) PRiSM Psychosis Study. Thro' a glass darkly: a distorted appraisal of community care. British foumol of Psychiotry. 175, $504-507$

Sayce, L., Crais, T. K. J. \& Boardman, A. P. (1991) The development of community mental health centres in the United Kingdom. Social Psychiotry and Psychiatry Epidemiology, 26, 14-20

Schinnar, A. P., Rothbard, A. B., Kanter, R., et ol (1990) An empirical literature review of definitions of severe and persistent mental illness. American journal of Psychiatry. 147, 1602-1608.

Scein, L. Suntos, A. (1990) Assertive Community Treatment of Persons with Severe Mental Ilness. New York: Norton.

Tyyor, R. Thornkeroft, G. (1996) Uses and limits of randomised controlled trials in mental health service research. In Mentol Health Outcome Meosures (eds G. Thornicroft \& M. Tansella). Heidelberg: Springer Verlag.

Teague, G. B., Bond, G. R. \& Drabe, R. E. (1998) Program fidelity in asser tive community treatment: development and use of a measure. Americon foumol of Orthopsychiatry, 68, 216-232.

Tharnicroft, G. A Coldbers, D. (1998) Hos Community Care Failed? Maudsiey Discussion Paper No. 5. London: Institute of Psychiatry

—, Strathdee G., Phelan, M., et of (19980) Rationale and design. PRiSM Psychosis Study I. British journol of Psychiotry, 173, 363-370.

—, Wykes, T., Holloway, F., et al (I9seb) From efficacy to effectiveness in community mental health services. PRiSM Psychosis Study 10. British foumal of Psychiatry, 173, 423-427.

Tyrer, P. (1998) Whither community care? British Journal of Psychiotry I73, 359-360.

—, Morgan, J., ven Horn, E., et al (1995) A randomised controlled trial of close monitoring of vuinerable psychiatric patients. Loncet, 345, 750-759.

Ux700 Group (1999) Comparison of intensive and standard case management for patients with psychosis. Rationale of the trial. British fournol of Psychiatry, 174, 74-78.

- (19\%) Comparison of Intensive and Standond Cose Management Programmes for Psychotic Potients. London: Department of Health.

Wylces, T., Leece, M., Thylor, R., et al (1998) Effects of community services on disability and symptoms. PRiSM Psychosis Study 4. British journal of Psychiatry, 173, 385390. 